\title{
Monitoring of BLDC Motor Load with Speed Feedback using Arduino and LABVIEW Interface
}

\author{
Ishrat Ali ${ }^{1}$, Ameen Uddin Ahmad ${ }^{2}$ \\ M. Tech Scholar, Al-Falah University, Dhauj, Faridabad, Haryana, India ${ }^{1}$ \\ Assistant Professor, Al-Falah University, Dhauj, Faridabad, Haryana, India ${ }^{2}$
}

\begin{abstract}
Today in industrial application, robotics, home appliances, etc. speed control of a motor is often required. In this paper We try to implement a BLDC motor speed control system. Basic idea of a speed control system is to maintain the speed of the motor at the desired value under several condition. Normally, The DC motor is a nonlinear device which have various changes in its speed because of change in load demand, disturbances. The tachometer is a very famous controller in industries so here we have implemented the Tachometer algorithm. Speed of motor is sensed by an optical switch which converted to feedback voltage. We use an IR sensor which detected the error signal on which The controller acts and generates appropriate control voltage. The PWM generator for control the speed of motor varies the duty cycle of the voltage supplied.
\end{abstract}

Keywords: BLDC, Arduino, LABVIEW, PWM generator

\section{INTRODUCTION}

Brushless DC motors are becoming more common in a variety of motor applications such as fans, pumps, appliances, robotic automation, and automotive drives. Main reason for their in hike in popularity are best speed versus torque characteristics, high efficiency, long life of operating, and operation without any noise. In addition to many advantages, the ratio of torque provided to the size of the motor is higher, design is useful in applications where space and weight are crucial factors. The stator of a BLDC motor is same as same to that of an induction machine but the windings are quite differently distributed. The distributed and sinusoidal are two different common distributions of the windings. A distributed winding will have a trapezoidal back EMF and a sinusoidal winding will have a sinusoidal back EMF. This application note will focus on BLDC motors with distributed stator windings. The rotor of a brushless DC motor is different in the fact that the rotor contains permanent magnets instead of additional windings. Not like a brushed DC motor, BLDC motor commutation in controlled electronically. the stator windings should be energized in a sequence, to rotate the BLDC motor. IR Sensors must be used to detect the position of the rotor in the motor, to make sure the motor controller is energizing coils in the correct sequence. When our rotor is spinning inner side of the motor, a North or a South Pole will travel by the IR Sensors which will cause the sensor to output which section of the rotor is traveled. We can implement all types of control algorithms on Brushless DC motor controller microcontrollers is the main difference of Brushless DC motor controller. sensor less control and the two main types of control algorithms are sensored . Sinusoidal and trapezoidal are the two different types of output that must be selected from after a control method is picked. In this paper we used a sensored control algorithm with IR sensor senses the speed of rotor at all various time. Here we use an Arduino microcontroller for the IR sensor output to know the present speed and variation in the duty cycle to get the desired speed of the rotor. Universal Serial Bus (USB) on some models, which are also used for loading programs from personal computers. The micro controllers are often programmed using a dialect of features from the programming languages $\mathrm{C}$ and $\mathrm{C}++$.

\section{PROPOSED METHODOLOGY AND BLOCK DIAGRAM}

The proposed block diagram is shown in figure 1. The blocks of which and control strategies is explained in this section

\section{BLDC and ESC}

Brushless DC electric motor (BLDC motors also known as electronically commutated motors are synchronous motors powered by DC electricity via an inverter/ switching power supply which produces an AC/ bi-directional electric current to drive each phase of the motor via a closed loop controller. The motor structural elements of a brush less motor system is typically permanent magnet synchronous motor, but can be a switched reluctance motor, or induction motor also. 


\title{
International Advanced Research Journal in Science, Engineering and Technology
}

\author{
Vol. 5, Issue 8, August 2018
}

Despite of the type used, an ESC break control information not as mechanical motion but as the case of a servo, but preferably in a way the switching rate of a network of field effect transistors varies. For brushed motors ESC systems are very different by design; by the result brushed ESC's are not amicable with brushless motors. Brushless ESC systems generally create a tri-phase AC power output of limited voltage from an onboard DC power input, to run brushless motors by sending a sequence of AC signals generated from the ESC's circuitry, employing very low impedance for rotation.

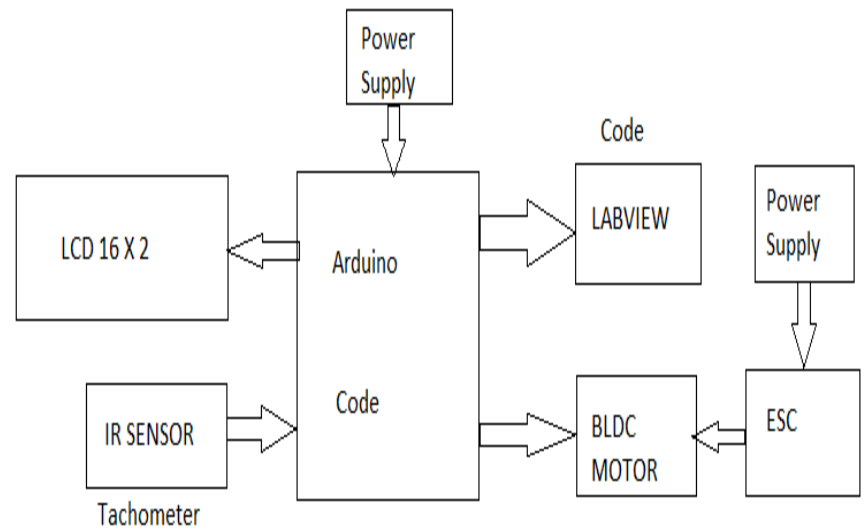

Figure 1: Block Diagram

\section{Controlling Technique}

PWM technique is best of the most famous speed control techniques for BLDC motor. According to this technique a high frequency chopper signal with specific duty cycle is multiplied by switching signals of VSI. so it is possible to change output voltage accordingly inverter by controlling duty cycle of switching pulses of inverter. The analog methods are prone to noise and they change with voltage and temperature change these are disadvantages of this. they endure changes due to component variation also. digital methods are more flexible compared to them. Main principle of generating PWM Counter is used to generate triangular wave. If the value of compare register is less than the value of triangular wave, then PWM is 1 , else PWM is 0.

The supply voltage is chopped at a fixed frequency with a duty cycle depending on the current error. Therefore, both the current and the rate of change of current can be controlled. The two phase supply duration is limited by the two phase commutation angles. The main advantage of the PWM strategy is that the chopping frequency is a fixed parameter; hence, acoustic and electromagnetic noises are relatively easy to filter. There are also two ways of handling the drive current switching: hard chopping and soft chopping. In the hard chopping technique, both phase transistors are driven by the same pulsed signal: the two transistors are switched-on and switched-off at the same time. The soft chopping approach allows not only a control of the current and of the rate of change of the current but a minimization of the current ripple as well. In this soft chopping mode, the low side transistor is left ON during the phase supply and the high side transistor switches according to the pulsed signal. In this case, the power electronics board has to handle six PWM signals. The duty cycle determines the speed of the motor. The desired speed can be obtained by is changing the duty cycle, it is a microcontroller which is used to control the duty cycle of BLDC motor. the mechanical commutation system utilized by a Brush DC Motor is replaced by An electronic Brushless DC Controller (also known as a Driver, or Electronic Speed Controller), and is required by most Brushless DC Motors to operate. either a IR Sensor or Back EMF (Electromotive Force) is used to identify the position of the rotor In a Brushless DC Motor controller. According to the knowledge of the orientation of the rotor is crucial to operating the Brushless DC Motor. Brushless DC Motor with The Controlling Effect uses IR Sensor help to detect the position of the rotor. This method is basically used in speed detection, current sensing, positioning, and proximity switching.

\section{ARDUINO Uno board type}

Arduino board designs can be use a different type of microprocessors and controllers. The boards are equipped with sets of digital and analog input/output (I/O) pins that may be interfaced to various expansion boards (shields) and other circuits. The boards feature serial communications interfaces, including Universal Serial Bus (USB) on some models, which are also used for loading programs from personal computers. The microcontrollers are typically programmed using a dialect of features from the programming languages $\mathrm{C}$ and $\mathrm{C}++$. 


\section{International Advanced Research Journal in Science, Engineering and Technology}

Vol. 5, Issue 8, August 2018

\section{LABVIEW Interface}

The GUI for monitoring was made on LABVIEW Software. Figure 2 gives front panel view of the LABVIEW Interface, and Figure 3 gives Block Diagram view of LABVIEW Interface for the proposed methodology.

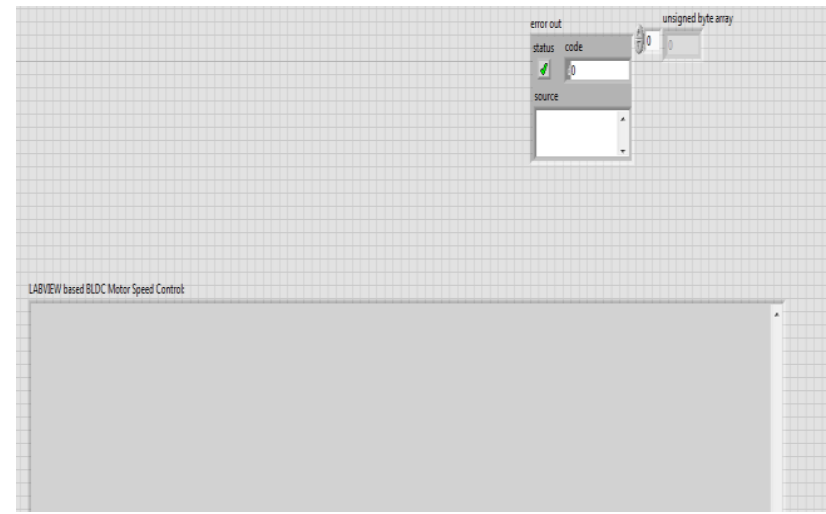

Figure 2: Front Panel LABVIEW

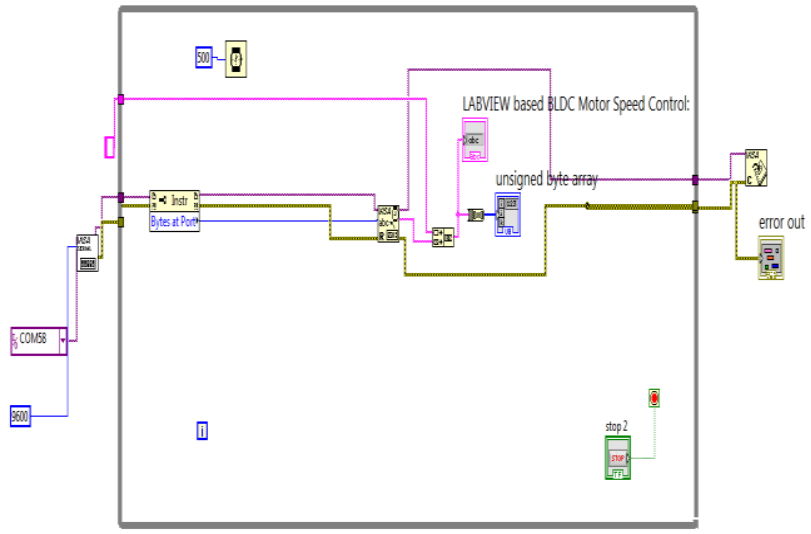

Figure 3: Block Diagram LABVIEW

\section{Results}

In figure 4, project implementation is shown for LabVIEW and Hardware model. It shows that it is an efficient way to find out load desired value of the motor and speeding it up for the same.

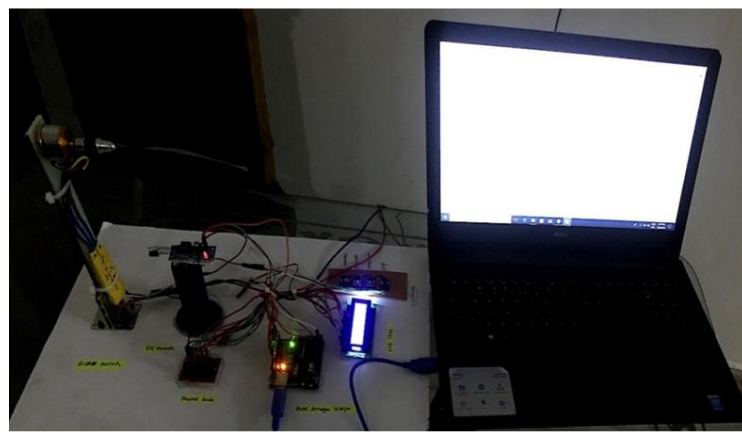

Figure 4: Project Implementation

The system once fully worked will not disable LABVIEW monitoring of the parameters of BLDC Motor. This paper presents the speed control method of BLDC Motor via LABVIEW technology. As the results of experiments, speed response and performance evaluation has been verified with different speed. Future scope of wireless automation includes usage of flexible networks of microcontroller based systems to monitor and control a bank of electrical gadget in commercial and residential arenas. Used networks would not only restricted to LABVIEW but they can also use Bluetooth, Wireless Fidelity (Wi-Fi), Radio Frequency Identification (RFID) and Zigbee etc. 


\title{
International Advanced Research Journal in Science, Engineering and Technology
}

\author{
Vol. 5, Issue 8, August 2018
}

\section{REFERENCES}

[1]. Brushless DC Motor Control using the LPC2141 Application Note; AN10661, NXP Semiconductors: Eindhoven, the Netherlands, October 2007.

[2]. Brushless DC (BLDC) Motor Fundamentals Application Note; AN885, Microchip: AZ, USA. 2003.

[3]. Burger, F.; Besse, P.A.; Popovic, R.S. New Single Chip Hall Sensor for Three Phases Brushless Motor Control. Sens. Actuat. A-Phys. 2000, 81, 320-323.

[4]. 3-Phase BLDC Motor Control with IR Sensor using 56000/E Digital Signal Controllers Application Note; AN1916, Freescale Semiconductor: TX, USA, 2005.

[5]. Anand Sathyan Ph.D Thesis -Digital PWM Control of Brush Less DC (BLDC) Motor Drives, Illinois Institute of Technology, Chicago, Illinois, December 2008.

[6]. Asian Journal of Applied Science and Technology (AJAST) Volume 1, Issue 7, Pages 10-14, August 2017 @ 2017 AJAST All rights reserved. Online ISSN: 2456-883X Publication Impact Factor: 0.825 Website: www.ajast.net Page | 14

[7]. A.Tashakori, M. Ektesabi, "Comparison of Different PWM Switching Modes of BLDC Motor as Drive Train of Electric Vehicles", World Academy of Science, Engineering and Technology, 67, 2012.

[8]. Ruta A. Bhave, Mitali S. Gogate, Ajay A. Maity, Priyanka D. Shivthare, "Wireless Automation of an Electrical Drive using Bluetooth", IJESRT, vol.2, issue 11, pp. 3291-3294, Nov. 2013.

[9]. Curt Franklin and Julia Layton, How Stuff Works, webpage on "How Bluetooth Works" [Online]. Available: http://electronics.howstuffworks.com/bluetooth.htm

[10]. M. A. Hassan, A. R. Abdullah, N. Bahari and A. Jidin, "Incorporating brushless DC motor in outdoor fan control of low voltage airconditioning system", Research and Development (SCOReD), 2013. IEEE Student Conference on, Putrajaya, 2013, pp.550-555.

[11]. iWRAP User Guide, Lab view technologies, March 25, 2011.

[12]. M. A. Hassan, A. R. Abdullah, N. Bahari and A. Jidin, "Incorporating brushless DC motor in outdoor fan control of low voltage airconditioning system," Research and Development (SCOReD), 2013 IEEE Student Conference on, Putrajaya, 2013, pp. 550-555.

[13]. Jianwen Shao, "Direct Back EMF Detection Method for Sensor less Brushless DC (BLDC) Motor Drives, M.S. Thesis, Virginia Polytechnic Institute and the State University.", Blacksburg, Virginia, 2003.

[14]. Texas Instrument, Appl. Note SPRABN7, pp. 1-16

[15]. Texas Instrument, Appl. Note SPRABQ9, pp 1-44

[16]. Nilsson, James William, and Riedel, Susan, Electric Circuits. Vol. 8. Prentice Hall, 2009.

[17]. P.C. Sen, Principles of Electrical Machines and Power Electronics, John Wiley \& Sons, Inc., 1997.

[18]. R. C. D. and R. H. Bishop, Modern Control Systems, 12th ed. Pearson, 2011.

[19]. Texas Instrument, Appl. Note INSTA SPIN Projects and Labs User's Guide, pp 8186. 